The Open Civil Engineering Journal
CrossMark
Content list available at: www.benthamopen.com/TOCIEJ/
DOI: $10.2174 / 1874149501711011158$

RESEARCH ARTICLE

\title{
Experimental vs. Numerical Simulations: Seismic Response of a Half Scale Three-Storey Infilled RC Building Strengthened Using FRP Retrofit
}

\author{
Federica Bianchi ${ }^{1}$, Roberto Nascimbene ${ }^{1, *}$ and Alberto Pavese ${ }^{2}$ \\ ${ }^{I}$ European Centre for Training and Research in Earthquake Engineering (EUCENTRE), Via Ferrata 1, 27100 Pavia, \\ Italy \\ ${ }^{2}$ University of Pavia, Via Ferrata 3, 27100 Pavia, Italy
}

Received: January 12, 2017

Revised: May 15, 2017

Accepted: July 10, 2017

\begin{abstract}
:
Background:

In the field of seismic analysis of structures, the use of appropriate Finite Elements software packages to manage more complex numerical models and to run more sophisticated analyses (such as nonlinear dynamic time-history analyses) in very short runtimes has increased significantly in the last decades.

In order to have confidence in the numerical results of these complex analyses, it has become an increasingly widespread practice to verify and validate the FE computers programs against literature case studies as well as experimental results. Focusing on this latter aspect, shaking-table experiments on real buildings play an important role in understanding the actual behaviour of such structures.
\end{abstract}

\section{Objective:}

In the present work, the numerical evaluation of the seismic response of a half scale three-storey infilled RC building that has been strengthened using composite materials (i.e. FRP retrofit) is carried out by adopting specific modelling techniques. The adequacy of the numerical modelling is then verified by comparing numerical results against experimental data.

Keywords: Existing buildings, Infilled RC building, FRP retrofit, Shaking table tests, Experimental vs. numerical results, Seismic analysis.

\section{INTRODUCTION}

Within the NEARB Project (Numerical and Experimental Assessment of Recommendations Inherent Existing Reinforce Concrete Buildings Included in OPCM 3274), in 2008 a series of shaking table tests were carried out at the Eucentre TREES Lab of Pavia, Italy (Laboratory for Training and Research in Earthquake Engineering and Seismology), with the aim of investigating the design aspects, as well as the damage patterns, peculiar of an existing three-storey reinforced concrete building, filled by non-structural masonry infilled walls.

The prototype structure was a masonry-infilled reinforced concrete building typical of most of the Mediterranean countries, which was designed and built according to the construction practice commonly adopted in Greece in the early 70's [1]. As it is well known, these kind of structures were designed before the introduction of the 'capacity design' principles in modern seismic codes, and thus by neglecting all the basic concepts for a good seismic behaviour, such as regularity (both in plan and elevation), adequate lateral resistance systems, detailed reinforcement, etc.

\footnotetext{
* Address correspondence to this author at the European Centre for Training and Research in Earthquake Engineering (EUCENTRE), Via Ferrata 1, 27100 Pavia, Italy; Tel: +3903825169827; E-mail: roberto.nascimbene@eucentre.it
} 
The test specimen (Fig. 1) was built on a small scale (1:2), but referring for many aspects to the full scale RC framed structure tested under pseudo-dynamic conditions at the ELSA Laboratory of Ispra, Italy, within the SPEAR Project (Seismic Performance Assessment and Rehabilitation of Existing Buildings [2]).

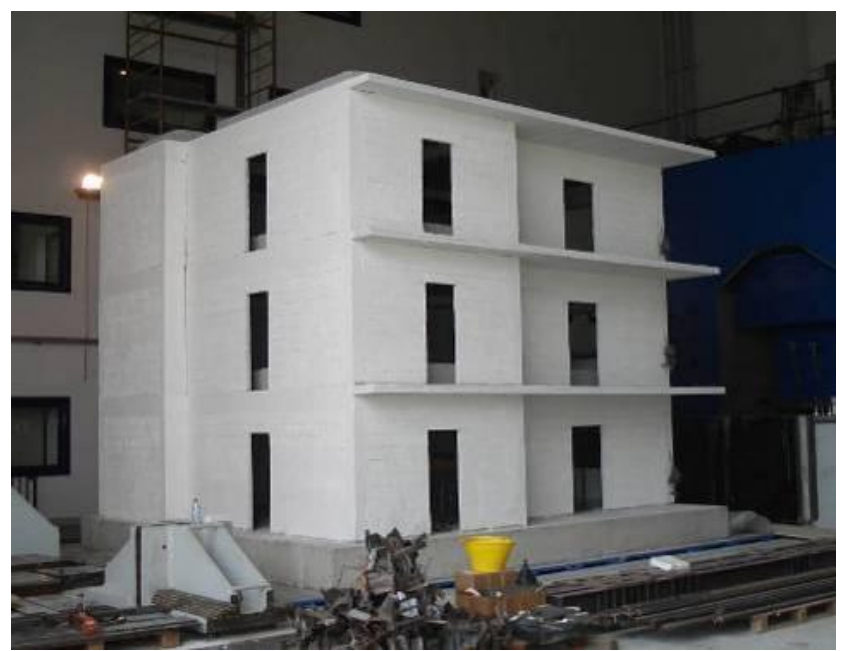

Fig. (1). Prototype building tested at the Eucentre TREES Lab.

The first part of the experimental tests campaign that was carried out in Pavia was focused on the evaluation of the seismic vulnerability of the infilled reinforced concrete building, the results of which were already presented and highlighted in several past studies [3, 4].

The 'original' prototype structure, which was seriously damaged by two simulated seismic events of increasing intensity, was then repaired and strengthened using composite materials (i.e. FRP retrofit) and new shaking table tests were finally performed in order to evaluate the effectiveness of this strengthening strategy.

Therefore, the present work will focus on the numerical evaluation of the seismic response of the retrofitted structure.

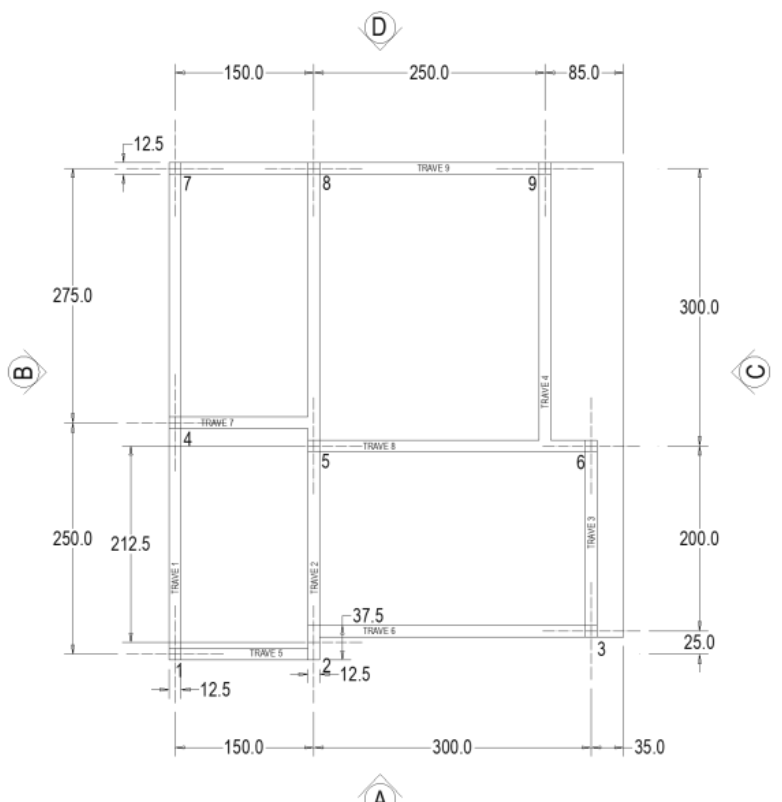

A)

Fig. (2). Plan view of the prototype building (dimensions in centimetres). 


\subsection{Brief Description of the Test Specimen}

For some practical reasons (e.g. the limitation due to the shaking-table dimensions), a real scale model was not feasible, hence a geometric scale factor was considered. As detailed in [5], this implies not only a reduction of the geometrical dimensions of the test specimen, but also that a time reduction and a mass scaling factors must be introduced in order to respect scaling similarity laws.

Therefore, the test specimen is a half scale, three-storey infilled reinforced concrete building, regular in elevation but highly irregular in plan. Its structural configuration in plan is represented in Fig. (2), in which are highlighted the main dimensions of the structure, whilst in Fig. (3) are shown two lateral views, A and B respectively.

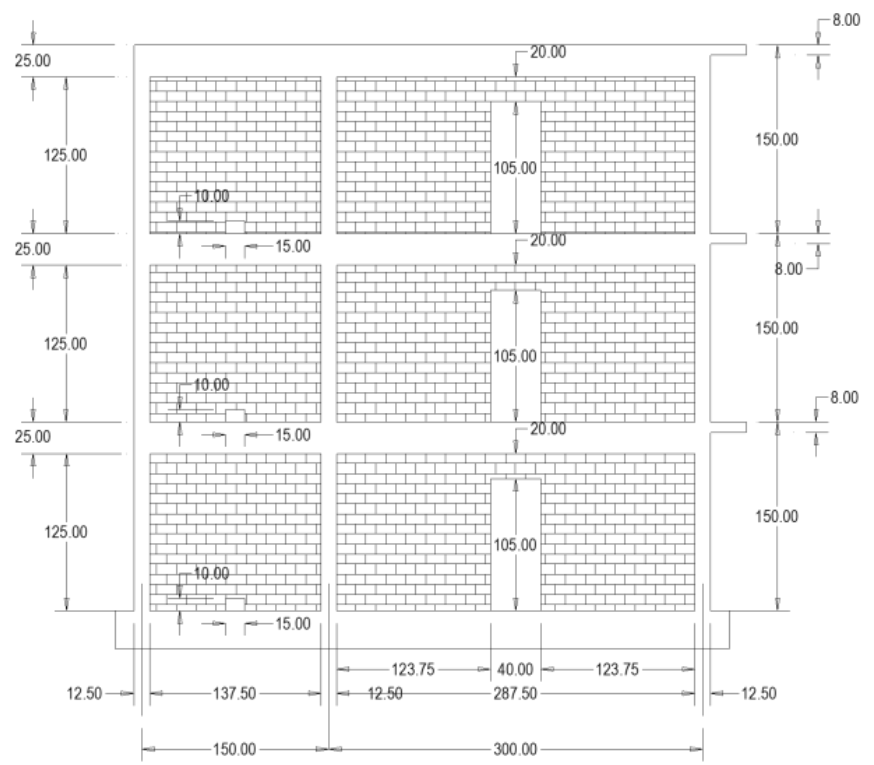

(a)

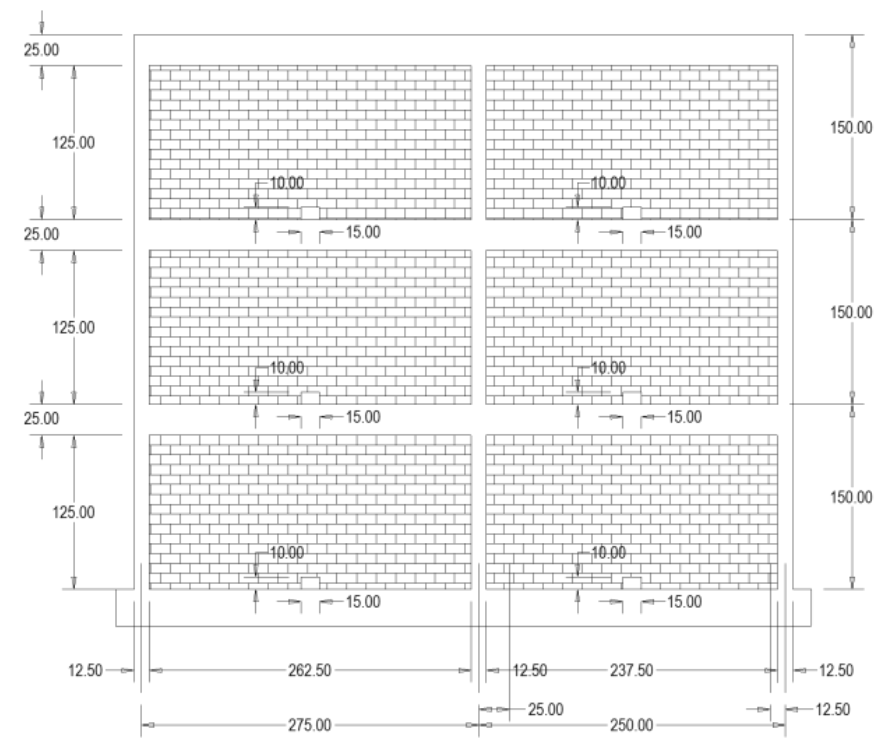

(b)

Fig. (3). Lateral views (A and $\mathbf{B})$ of the prototype building (dimensions in centimetres).

As it can be noted in Fig. (2), the building presents two main peculiarities, the former is that two beams are not directly supported by columns, the latter is the presence of a beam-column joint with a high structural eccentricity (i.e. Column 2). 
The building consists of nine cast-in-place RC columns per floor, connected by RC beams. The cross sections dimensions of the columns are $125 \times 125 \mathrm{~mm}$, with the exception of Column 2 , which is $125 \times 375 \mathrm{~mm}$, whilst the beams are $125 \times 250 \mathrm{~mm}$. The reinforcement is made of smooth rebars with yielding strength $\left(\mathrm{f}_{\mathrm{y}}\right)$ equal to $370 \mathrm{MPa} 180^{\circ}$ hookended. The steel reinforcement of the columns is made of $\varnothing 6$ and the stirrups are $\varnothing 3$ spaced at 70 mm; there is lack of stirrups in the beam-column joints. Regarding the concrete material, it has a characteristic compression strength $\left(\mathrm{f}_{\mathrm{ck}}\right)$ equal to $25 \mathrm{MPa}$.

The floor slabs are cast-in-place concrete slabs. They have a thickness of $120 \mathrm{~mm}$ and are reinforced by $2 \varnothing 6$ electro-welded reinforcement mesh $(10 \times 10 \mathrm{~cm}$ grid). Detailed information about structural beam member dimensions and reinforcing bars may be found in [2].

The infill panels are made of cellular concrete Gasbeton ${ }^{\circledR}$ RDB blocks with dimensions $156 \times 125 \times 50 \mathrm{~mm}(\mathrm{w} \times \mathrm{h}$ $x \mathrm{t}$ ) which have been obtained by cutting off the available blocks, in order to have characteristics similar to those of a typical hollow masonry infill. Further design details can be found in [6, 7].

As noted above, in order to perform a representative simulation of the full scale structure, special attention was addressed in the application of appropriate scale factors, as detailed in [5]; in particular, additional masses were applied to the test specimen, as shown in Fig. (4).

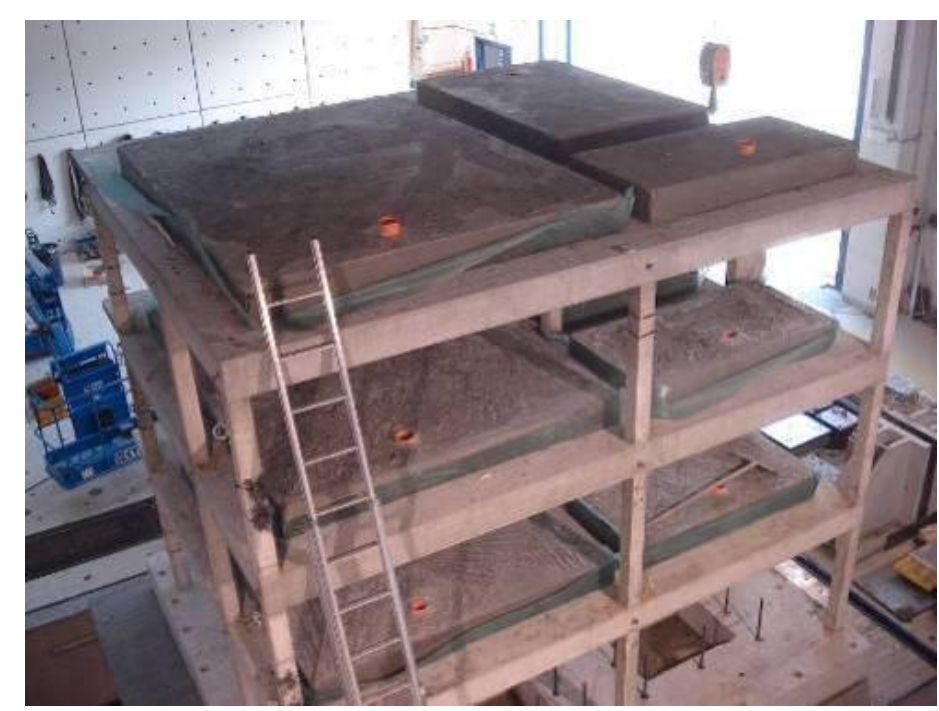

Fig. (4). Additional masses applied to the test specimen.

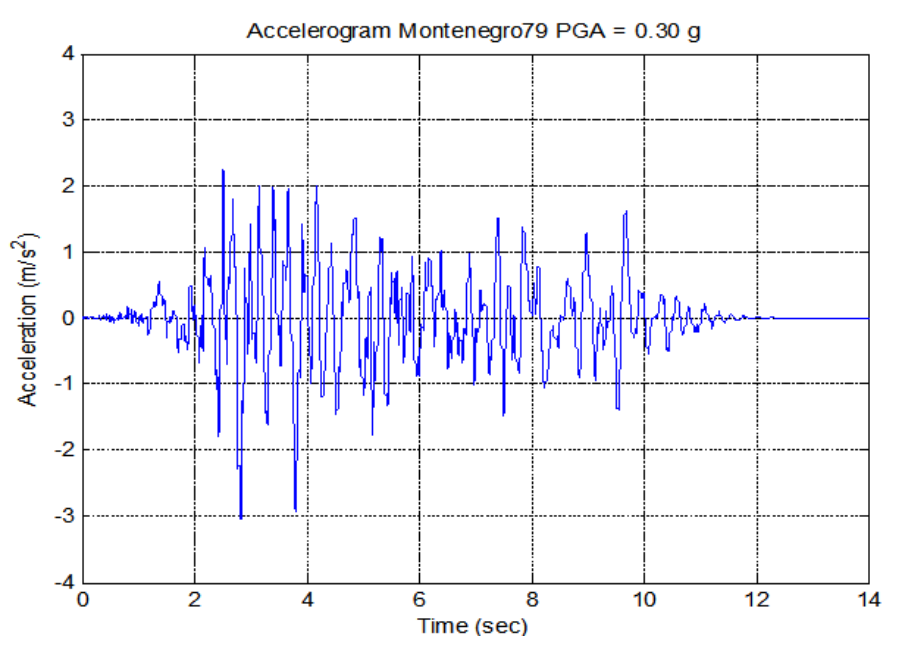

Fig. (5). Herceg-Novi accelerogram $(\mathrm{PGA}=0.3 \mathrm{~g})$. 


\subsection{First Experimental Tests Campaign}

The specimen was tested under dynamic conditions by means of shaking table tests. The dynamic tests were performed using the same ground motion employed for the pseudo-dynamic tests of the full scale building (tested at the ELSA Laboratory of Ispra within the SPEAR Project), i.e. the Montenegro 1979 accelerogram (Herceg-Novi station).

The original ground motion was scaled to different levels of PGA (0.08 g, $0.30 \mathrm{~g}$ and $0.54 \mathrm{~g})$, and was applied to the longitudinal direction of the building ( $\mathrm{Y}$ axis in Fig. 2), in order to simulate earthquakes of increasing intensities (minor, moderate and severe, respectively).

Fig. (5) represents the moderate ground motion that was applied at the base of the structure.

During the first experimental test sequences, the infilled reinforced concrete structure suffered a noticeable damage, in particular in the column elements of the first two storeys, which exhibited horizontal cracking at the beam-column interface (an example is shown in Fig. 6), whilst the behaviour of the beam elements was essentially elastic.

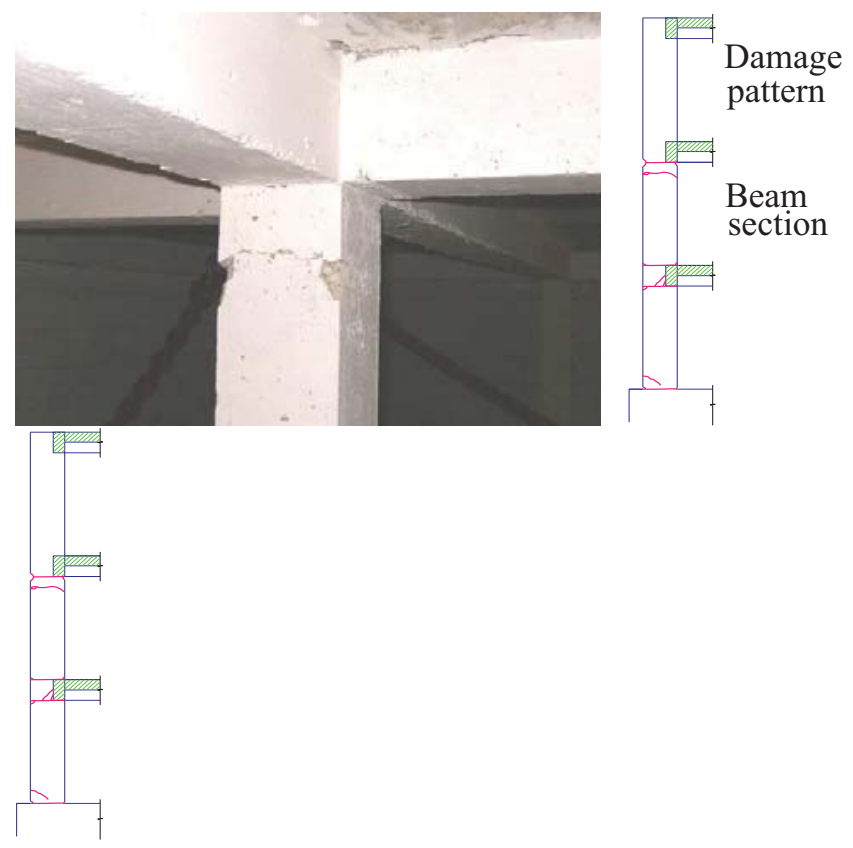

Fig. (6). A) Damage at the top end of Column $5\left(1^{\text {st }}\right.$ floor $)$ B) Damage of the column after the test at $0.54 \mathrm{~g}$.

In particular, in Column 2 (the one with rectangular dimensions) the damage was more pronounced, with cover spalling and buckling of longitudinal reinforcing bars, as shown in Fig. (7).

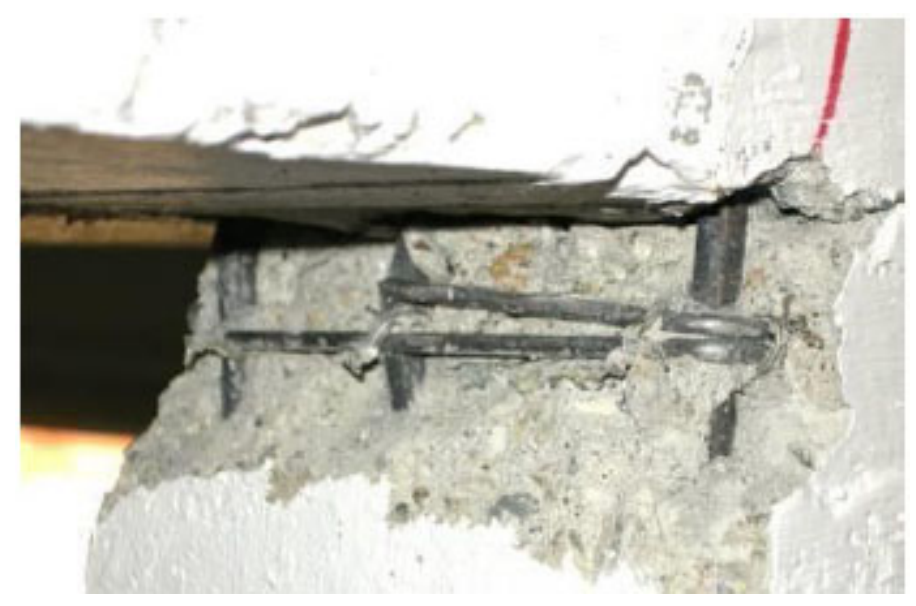

Fig. (7). Damage of Column 2. 


\section{MATERIALS AND METHODS}

\subsection{Strengthening Using Composite Materials}

Therefore, at the end of the experimental tests, and after the removal of the collapsed infills, the damaged structural elements were repaired with adequate epoxy resins and then strengthened using composite materials (i.e. FRP retrofit). FRP layers were applied to all the columns and the beam-column joints of the first two storeys, in order to increase the sections confinement and to avoid tensile failures, with the exception of the inner column (Column 5) and one outer column (Column 6), since these elements were already confined by the adjacent structural members.

Fig. (8) shows the final steps of application of the FRP strengthening to a beam-column joint (further details about the retrofitting of concrete structures by FRPS can be found in [8] and [9]).

The retrofitted structure was then infilled with new Gasbeton ${ }^{\circledR}$ RDB blocks, as shown in Fig. (9).

New shaking table tests were finally performed in order to evaluate the effectiveness of this strengthening strategy. During the shaking table test r.c. frame members and infilled panels were monitored using a machine vision system [10] allowing a careful observation of deformations and damage progression resulting from the application of the seismic loads. In particular, in Fig. (10) it is possible to observe the distribution of cracking in one of the infill panels at the base of the structure (lateral view $\mathrm{C}$ ).
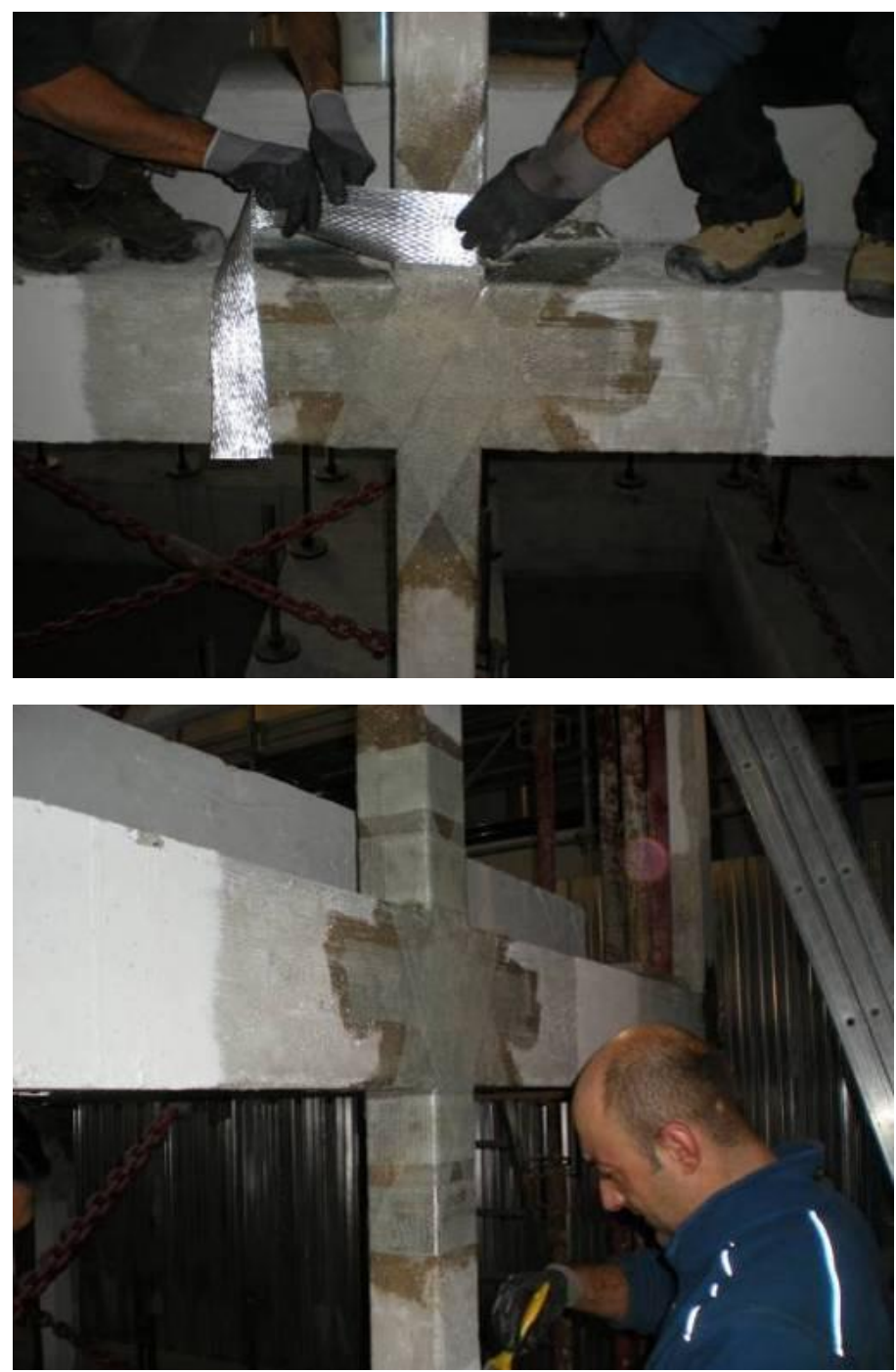

Fig. (8). Final steps of the application of FRP strengthening to a beam-column joint. 


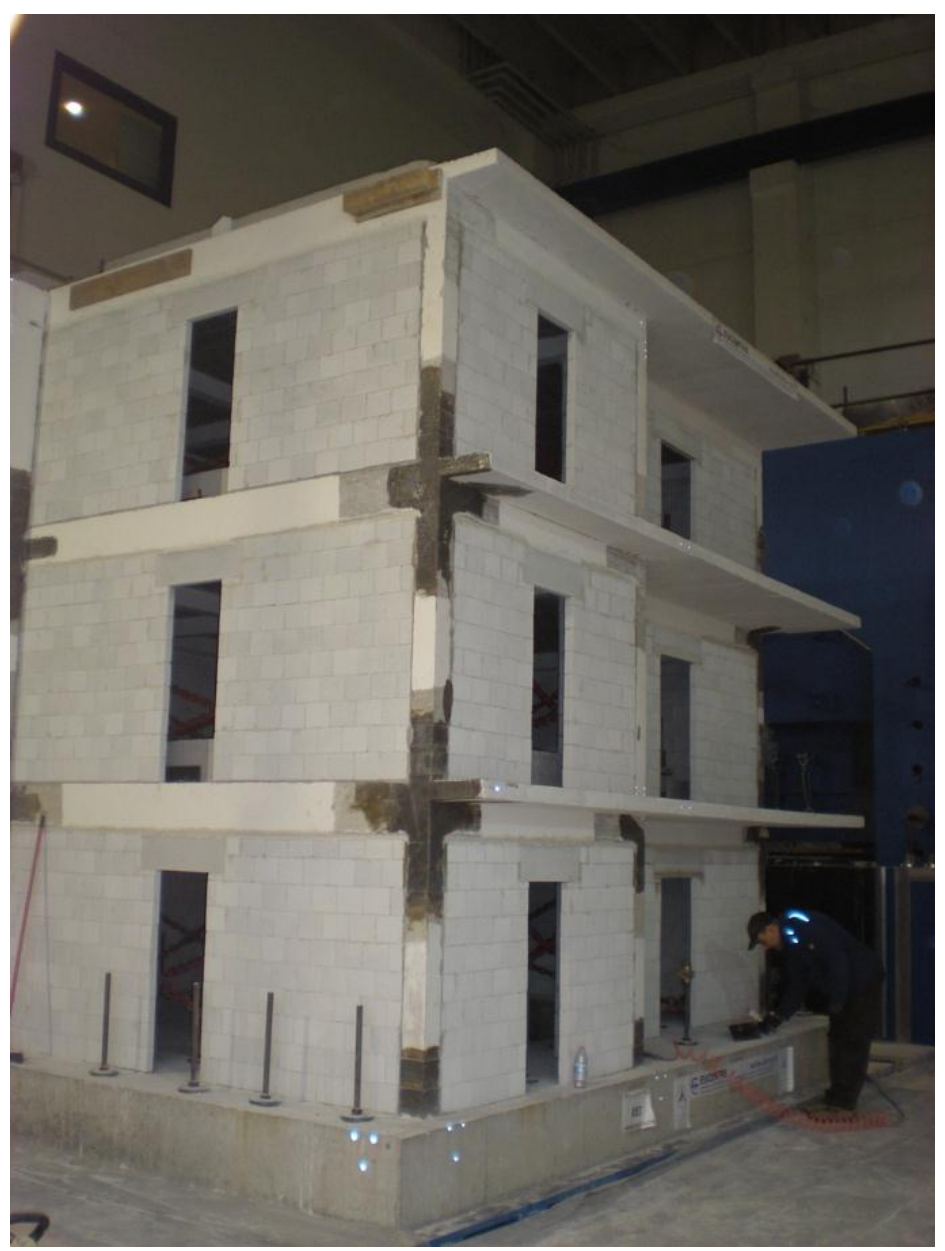

Fig. (9). Test specimen of the half scale three-storey infilled RC building strengthened using FRP retrofit.

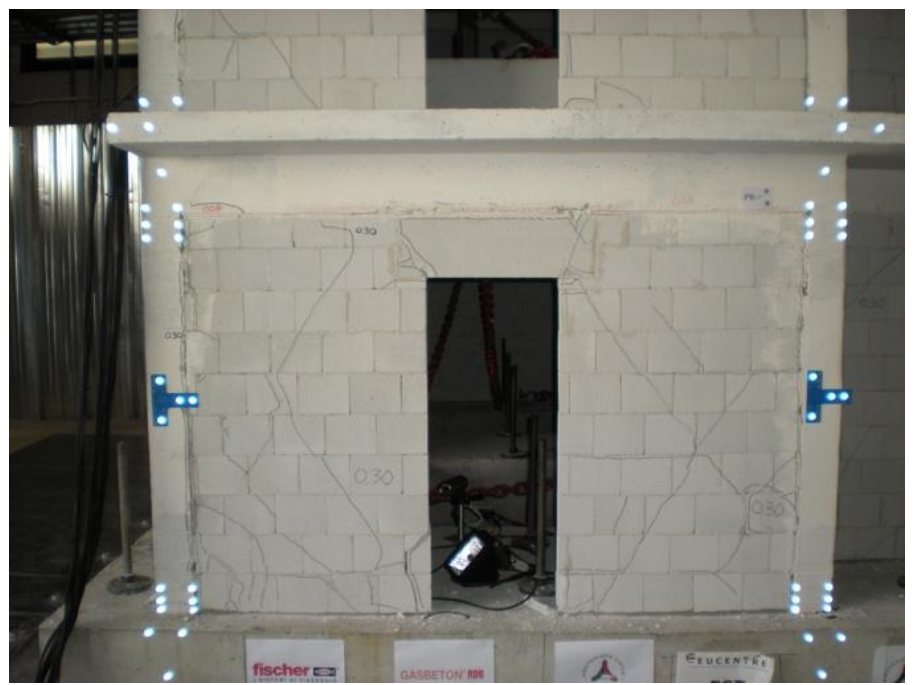

Fig. (10). Cracking in the infill panels after the test at $0.3 \mathrm{~g}$ on the retrofitted structure.

\subsection{Numerical Modelling of the Strengthened Building}

In this study the numerical evaluation of the seismic response of the strengthened building was performed by adopting specific modelling techniques.

All the numerical analyses were carried out using the Finite Element package SeismoStruct [11], a fibre elementbased program for seismic analysis of framed structures capable to take into account both geometric nonlinearities and 
material inelasticity, as well as the interaction between axial force and transverse deformation of the element. Furthermore, it was extensively quality-checked and validated, as described in its Verification Report, in particular through comparison with experimental results.

Within this analytical tool, RC columns and beams were modelled through 3D force-based inelastic frame elements with five integration sections per member and an adequate number of fibres (used in section equilibrium computations). The stress-strain behaviour of the reinforcing steel was described by the nonlinear model of [12], as modified by [13] including isotropic strain hardening effects, whereas the concrete material was modelled through the uniaxial nonlinear constant confinement concrete model that follows the relationship proposed by [14] (later modified by [15] for numerical stability reasons under large displacements/ deformations).

In order to take into account the increase of the section confinement due to the FRP retrofitting of the damaged columns, with respect to the original numerical model the section properties of the aforementioned columns were modified by assigning appropriate FRP wraps (defining the number of applied layers, as well as the radius of rounding of the corners R).

A four-node inelastic infill panel element, as developed by [16], was employed for modelling the nonlinear response of the infill panels. Each panel has been calibrated referring to [17] and [18] and is represented by six strut members; each diagonal direction features two parallel struts to carry axial loads across two opposite diagonal corners and a third one to carry the shear from the top to the bottom of the panel.

The slabs were modelled by introducing a rigid diaphragm in the X-Y plane at each floor level. The connection between Column 6 and the adjacent beams was modelled as rigid through rigid links. Finally, all foundation nodes were considered as fully restrained against rotations and translations.

Two 3D views of the Finite Element model used to reproduce the test specimen are represented in Fig. (11). The dark grey colour of some column elements indicates the strengthened elements.
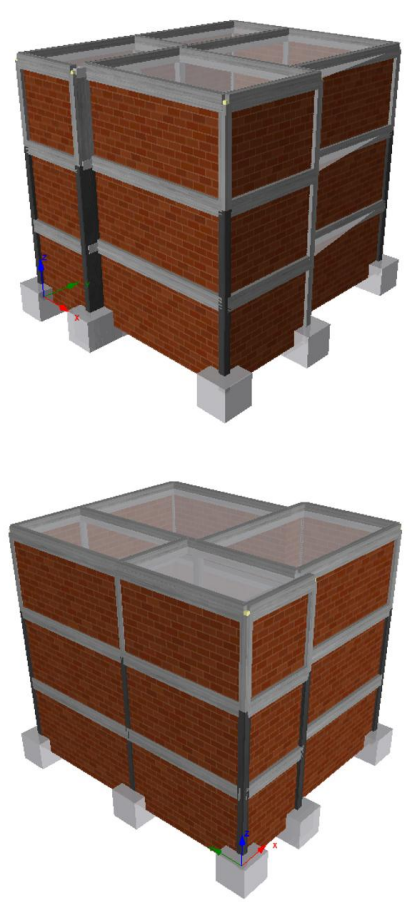

Fig. (11). 3D views of the finite element model used to reproduce the test specimen.

Regarding the applied masses, they were distributed along columns and beams, in order to represent the self-weight of the frame, as well as the permanent and live loads of the slabs.

In order to perform a nonlinear dynamic time-history analysis, the same scaled Herceg-Novi record with moderate intensity (PGA $=0.3 \mathrm{~g}$ ), which was employed in the analyses of the 'pre-retrofitted' structure, was applied to all the base nodes of the structure along the $\mathrm{Y}$ direction. 


\section{RESULTS AND DISCUSSION}

\subsection{Comparison Between Numerical and Experimental Results of the Retrofitted Building}

The comparison between experimental and analytical results of the retrofitted prototype building, in terms of maximum relative displacements in correspondence of Column 6 and Column 4 respectively, and recorded during the application of the moderate ground motion (PGA $=0.3 \mathrm{~g})$, is shown below in Figs. (12 and 13), in which it is possible to observe that the predictions of the analytical model are in close agreement with the experimental results.

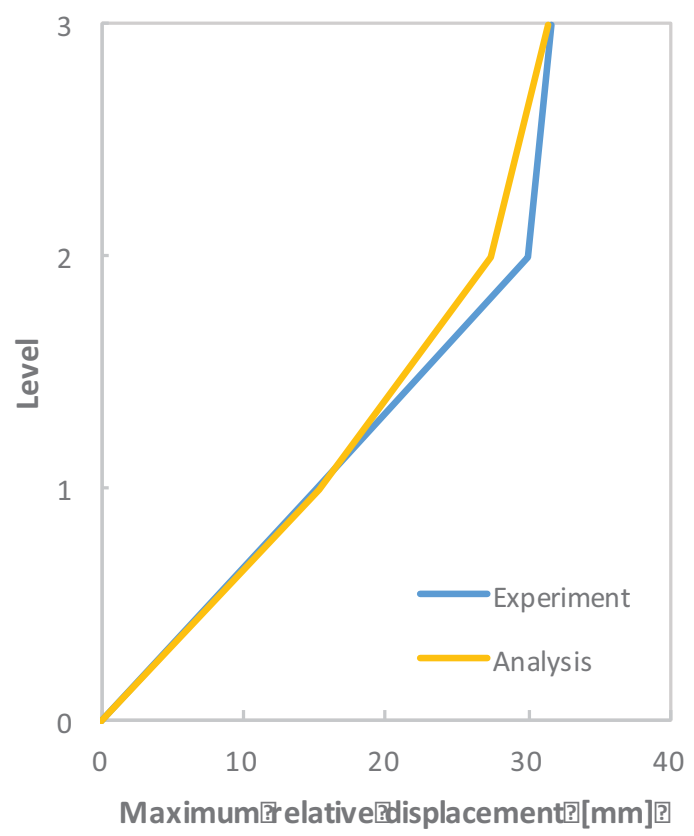

Fig. (12). Experimental vs. Analytical results - maximum relative displacement of C6-floor level.

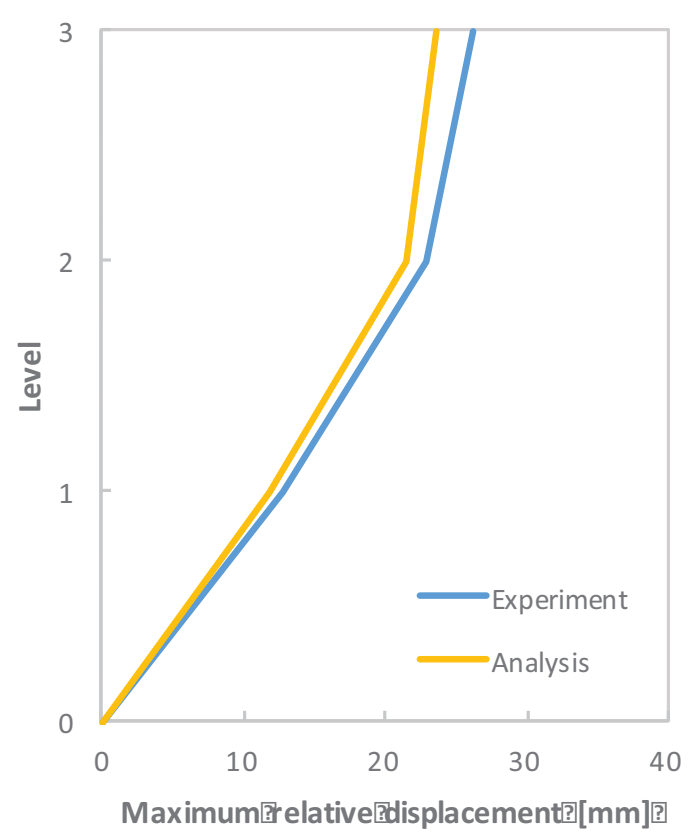

Fig. (13). Experimental vs. Analytical results - maximum relative displacement of C4-floor level. 
Furthermore, for the same record, Fig. (14) shows the comparison between experimental and analytical results in terms of maximum storey accelerations (in ' $\mathrm{g}$ ') observed at the centre of mass of the building.

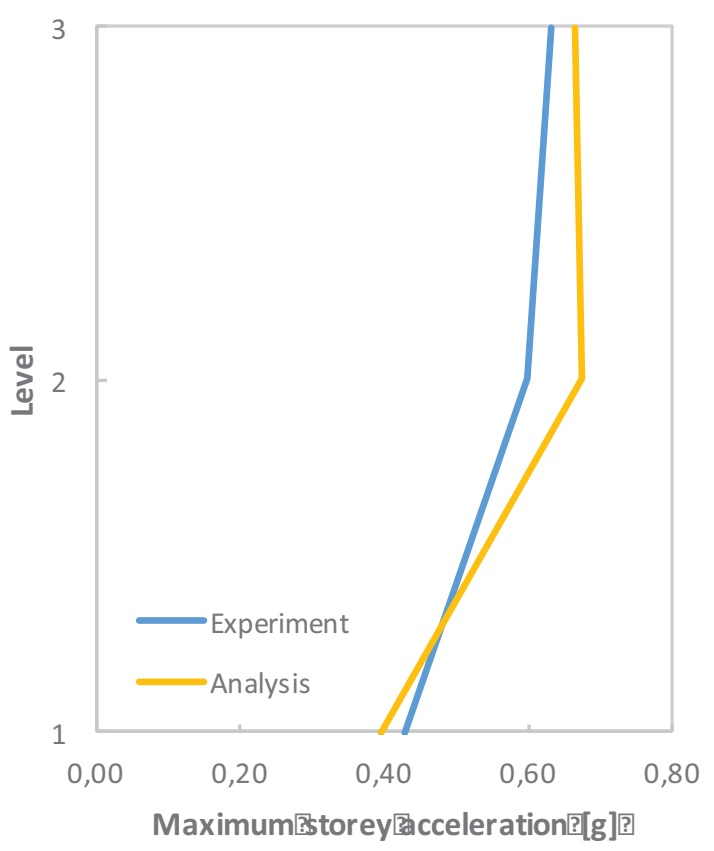

Fig. (14). Experimental vs. Analytical results - maximum storey acceleration at cdm-floor level.

\subsection{Comparison Between Numerical and Experimental Results of the Original Building (as Built)}

For completeness, in addition to the previous results, the comparison between numerical predictions and experimental data of the original building, in terms of maximum interstorey drift, is shown in Fig. (15). Also in this case, it is possible to observe that the predictions of the analytical model are in agreement with the experimental results; particularly the numerical drifts of the first two storeys are close to the experimental ones.

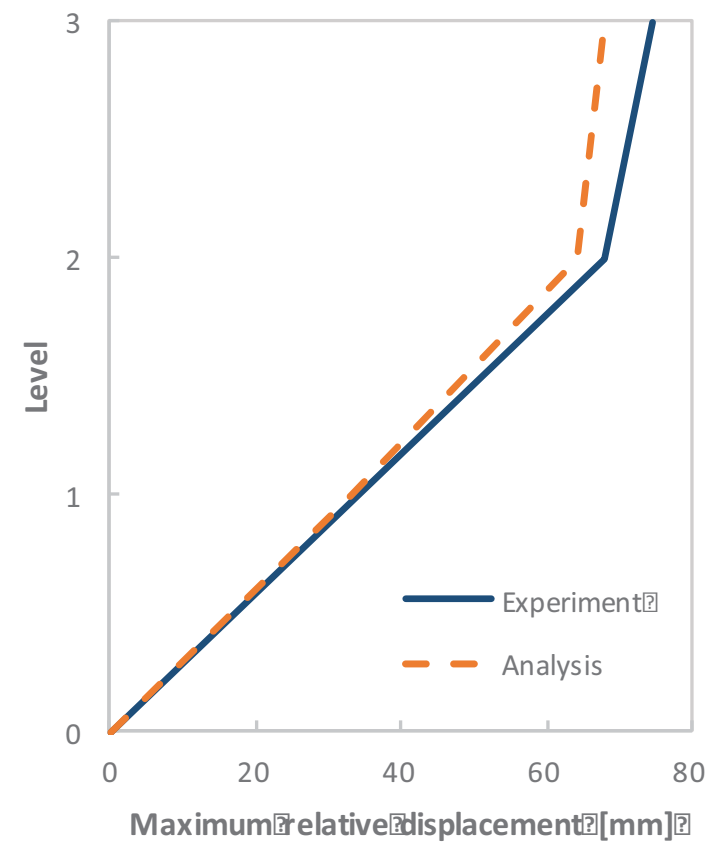

Fig. (15). Experimental vs. Analytical results - maximum relative displacement. 


\section{CONCLUSION}

In the present study the numerical evaluation of the seismic response of a half scale three-storey infilled $\mathrm{RC}$ building, strengthened using composite materials (i.e. FRP retrofit), was carried out by adopting specific modelling techniques in terms of section confinements. The adequacy of the numerical modelling was then verified by comparing numerical results against experimental data.

Based on the results presented above, it is possible to conclude that the nonlinear time-history analyses were able to predict relatively well the behaviour of the building, particularly in terms of storey displacements, however further investigations are clearly needed.

For completeness, the experimental results of the original structure (as built) have been compared in terms of maximum interstorey drift with the numerical simulations.

\section{CONSENT FOR PUBLICATION}

Not applicable.

\section{CONFLICT OF INTEREST}

The authors declare no conflict of interest, financial or otherwise.

\section{ACKNOWLEDGEMENTS}

The authors would like to thank the assistance of Dr. Igor Lanese in the provision of the experimental results and of Prof. Alberto Pavese as the coordinator of all experimental activities at the EUCENTRE Laboratory, as well as the Italian Civil Protection Agency that has founded the NEARB project.

\section{REFERENCES}

[1] M.N. Fardis, "Design of an Irregular Building for the SPEAR Project - Description of the 3-Storey Structure", Research Report, University of Patras, Patras, Greece, 2002

[2] M.N. Fardis, and P. Negro, "Seismic Performance Assessment and Rehabilitation of Existing Buildings", Proc. of the Spear international workshop, 2006 Ispra, Italy.

[3] A. Pavese, I. Lanese, and R. Nascimbene, "Seismic vulnerability assessment of an infilled reinforced concrete frame structure designed for gravity loads", J. Earthquake Eng., vol. 21, pp. 267-289, 2016.

[4] R. Nascimbene, "Numerical Model of a Reinforced Concrete Building: Earthquake Analysis and Experimental Validation", Period. Polytech. Civ. Eng., vol. 59, no. 4, pp. 521-530, 2015. [http://dx.doi.org/10.3311/PPci.8247]

[5] I. Lanese, F. Marazzi, and R. Nascimbene, "Il cambiamento di scala delle strutture per la verifica sismica su tavola vibrante di un telaio in c.a. progettato per carichi verticali", Ing. Sism., vol. 4, pp. 13-25, 2008.

[6] I. Lanese, "Valutazione numerico-sperimentale del comportamento sismico di un edificio esistente progettato per soli carchi verticali", MEng thesis, University of Pavia, Pavia, Italy, 2007.

[7] A. Pavese, I. Lanese, M.P. Scovenna, R. Franzolin, F. Lunghi, H. Airouche, C. Casarotti, and S. Peloso, "NEARB Project: Numerical and Experimental Assessment Recommendations inherent existing R.C. buildings included in OPCM 3274", Final research report, 2008.

[8] FIB, "Retrofitting of Concrete Structures by Externally Bonded FRPS, with Emphasis on Seismic Applications", In: FIB Bulletin n. 35., Federation Internationale du Beton, 2006, p. 220.

[9] D.A. Bournas, A. Pavese, and W. Tizani, "Tensile capacity of FRP anchors in connecting FRP and TRM sheets to concrete", Eng. Struct., vol. 82, pp. 72-81, 2015. [http://dx.doi.org/10.1016/j.engstruct.2014.10.031]

[10] F. Lunghi, A. Pavese, S. Peloso, I. Lanese, and D. Silvestri, "Computer vision system for monitoring in dynamic structural testing", Geotech., Geol. Earthquake Eng., vol. 22, pp. 159-176, 2011. [http://dx.doi.org/10.1007/978-94-007-1977-4_9]

[11] Seismosoft, "SeismoStruct - A computer programme for static and dynamic nonlinear analysis of frames structures", 2016.

[12] M. Menegotto, and P.E. Pinto, "Method of analysis for cyclically loaded R.C. plane frames including changes in geometry and non-elastic behaviour of elements under combined nor-mal force and bending", Symposium on the Resistance and Ultimate Deformability of Structures Acted on by Well Defined Repeated Loads, , 1973pp. 15-22.

[13] F.C. Filippou, E.P. Popov, and V.V. Bertero, "Modelling of R/C joints under cyclic excitations", J. Struct. Eng., vol. 109, no. 11, pp. 2666-2684, 1983.

[http://dx.doi.org/10.1061/(ASCE)0733-9445(1983)109:11(2666)] 
[14] J.B. Mander, M.J. Priestley, and R. Park, "Theoretical stress-strain model for confined concrete", J. Struct. Eng., vol. 114, no. 8, pp. 1804-1826, 1988. [http://dx.doi.org/10.1061/(ASCE)0733-9445(1988)114:8(1804)]

[15] J.E. Martinez-Rueda, and A.S. Elnashai, "Confined concrete model under cyclic load", Mater. Struct., vol. 30, no. 197, pp. 139-147, 1997. [http://dx.doi.org/10.1007/BF02486385]

[16] F.J. Crisafulli, "Seismic Behaviour of Reinforced Concrete Structures with Masonry Infills", PhD Thesis, University of Canterbury, Christchurch, New Zeland, 1997.

[17] L.D. Decanini, C. Gavarini, and S.H. Bertoldi, "Telai tamponati soggetti ad azioni sismiche un modello semplificato confronto sperimentale e numerico", 1993.

[18] L.D. Decanini, C. Gavarini, S.H. Bertoldi, and F. Mollaioli, "Modelo simplificado de Paneles de Mamposteria con Aberturas incluidos en marcos de concreto reforzado y metalicos. Comparacion y calibracion con resultados experimentales y numericos", Proceedings of the 9th International Seminar on Earthquake Prognostics, 1994 San Josè, Costa Rica.

(C) 2017 Bianchi et al.

This is an open access article distributed under the terms of the Creative Commons Attribution 4.0 International Public License (CC-BY 4.0), a copy of which is available at: https://creativecommons.org/licenses/by/4.0/legalcode. This license permits unrestricted use, distribution, and reproduction in any medium, provided the original author and source are credited. 